\title{
Computer Digital Art Innovation of Traditional Dyeing Technology
}

\author{
Yanli Hu \\ Jiangxi garment college, School of management, Nanchang, jiangxi \\ 190878023@qq.com
}

Keywords: Digital design; Tie pattern; Innovation pattern; Software technology

\begin{abstract}
In the industrial production background, traditional dyeing technology can not adapt to the large-scale mass production. The representative of the computer software to simulate the traditional tie dye patterns are divided into the following two operations, one is based on the re combination of pattern design decomposition of the original graphics; second using Photoshop computer software to imitate manual tie pattern. Form a similar tie dyed texture effects with the former, the latter for varied shape and color collocation pattern, change the restriction of the traditional Handmade in production, style target obtained by printing process. But the design of analog electronic technology dye patterns more blunt. How to combine the traditional dyeing technology and digital technology, more subtly, is one of the key research of this paper.
\end{abstract}

\section{Introduction}

The traditional tie dye with unique artistic charm, spread widely and has a far-reaching influence in the world, but in the end because of the restrictive factors of the manual production led to high market prices, easy to fade, the fabric pattern design are quite unpredictable and other problems which restrict the development of the traditional craft. With the continuous development of science and technology, all kinds of new computer software tools have been applied to the traditional arts and crafts, design art and other different types of vivid and new combination of science and technology and art. Different from the traditional dyeing technology of the original production techniques, the digital art design material creators will be drawn by the traditional paper into computer software application, the use of digital software to create design works of every kind of technological strengths, to give people a hitherto unknown new visual feast. Therefore, to break through the traditional tie dye art techniques, digital art has certain reference value in theory research and practical application of the powerful modern tie dyeing pattern design.

\section{The Advantages of Digital Software Design}

Tie dye, farm blue cloth, these traditional batik dyeing methods, meet digital software today after a new concept. That change is different from that of traditional dyeing process, can be in any textile materials using modern dyeing process of high technology and a variety of special techniques, the traditional process reflects the aesthetic characteristics of modern art aesthetic on the plane, stereo or monochrome and multicolor blending to produce new graphic art creation process. In the information age, digital art with digital processing technology as the main means, provide reference for modern textile art, and has become an important tool to create a new graphical design language and the main contemporary designer for modern design.

It is a typical representative of the digital simulation software of traditional tie dye patterns can be divided into the following two kinds of operation, the first is to reorganize the original graphic pattern design decomposition (Fig. 1.1,1.2); second is to imitate the pattern by using Photoshop computer software tie manual painting method. (Fig. 1.3,1.4) to form a similar tie dyed texture effects with the former, and the latter varied shape change pattern for color collocation, can change the restriction of the traditional Handmade in production, to achieve high volume. But this technology through the digital simulation dye patterns appear stiff, how to combine the traditional dyeing technology and method of digital technology more harmonious, is one of the focus of this study. 


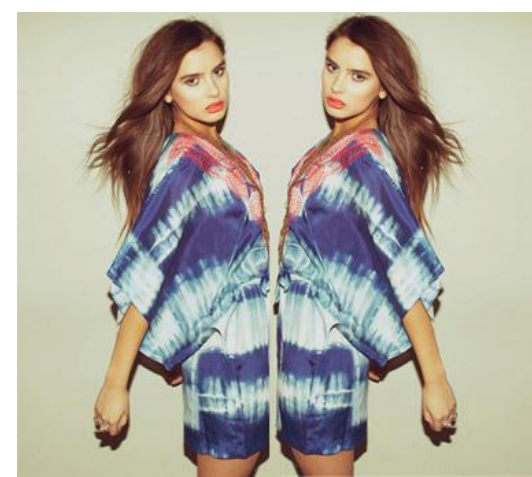

Figure 1.1 parallel sewing effect of traditional tie dye

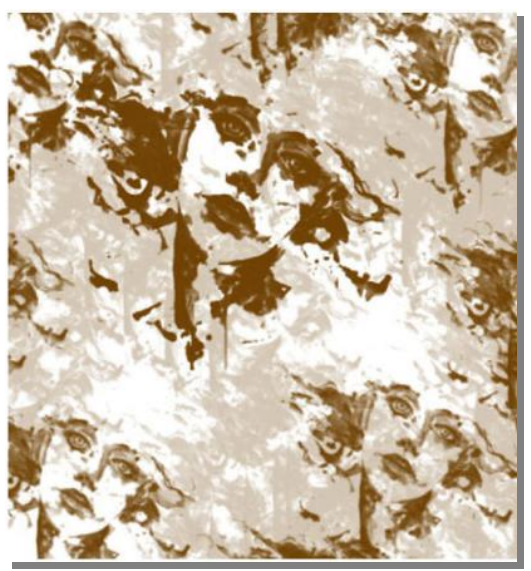

Figure 1.3 computer digital simulation dye patterns

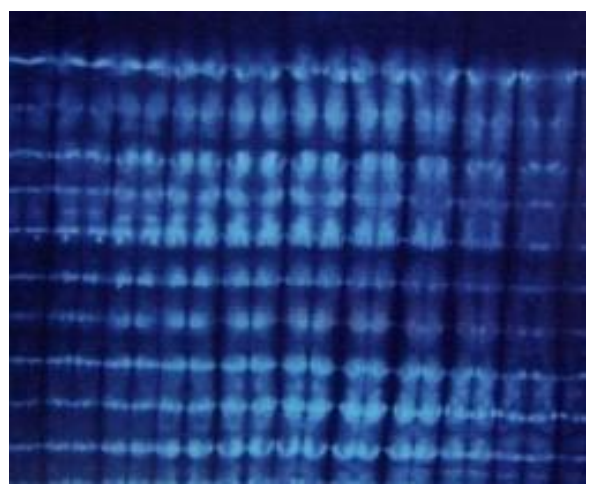

Figure 1.2 uses the computer software to design the new pattern according to the original image.

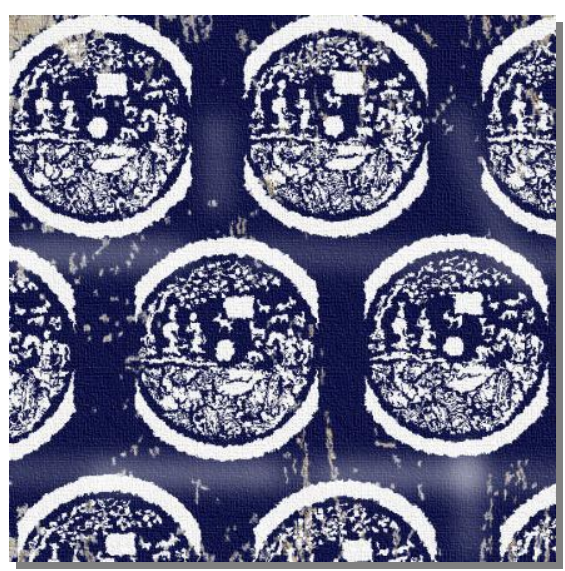

Figure 1.4 computer digital simulation dye patterns

Figure 1.3, 1.4 using Photoshop computer software to imitate manual painting method of tie dye pattern

\section{Digital Changes in Traditional Tie Dye Process}

The natural dyeing technology and the texture is received and the use of people love, so in the digital design pattern not only remain in the digital technology to imitate tie dye patterns, but will combine effect of dyeing technology and digital technology, breaking the original single pattern pattern and stylized manual performance techniques, combined with modern new technology, the change of the dyeing technology of design and creation, this is precisely the solution of digital tie-dye art innovation way good.

The traditional tie dye graphics is very diverse, finishing up can find some changes in the law, form the pattern change of the main elements of "dot" and "line" and "surface" three basic elements. The manual tie dye technique formed by the "point", "line" and "surface" three elements of the unit elements scanned into the computer software, then these factors selected to modify the collation, copy, collage and so on combinations of recombinant innovation design using digital design techniques, the combination of new pattern design units a new pattern, achieved through the use of printing technology for mass production. The new technology not only can be retained the texture feature of the traditional tie dye and flavor of natural and simple, and can be free to design other rich patterns, and the use of digital technology changes color collocation, independent position exchange, fabric texture simulation and so on, but also improve production efficiency, reduce the cost. 
Let us through the view point of digital technology in the case of dye patterns in dye patterns: firstly, innovation point of traditional tie dye patterns after scanning into the computer through the levels of uniform color, the unit element can be a combination of one or more blocks on the dyed fabric pattern. Then use the Photoshop software to copy, collage, or dots, lines, a geometric, abstract shape combination arrangement, can avoid frequent manual technology leakage tie, tie dye, color bar fault leakage error, can also be collage traces formed by repair repair a tool or tool in the stamp tool to repair it, the repair can be better to keep the original pattern of manual tie marks, is the key to obtain the genuine. (as shown in Fig. 2.1,2.2,)

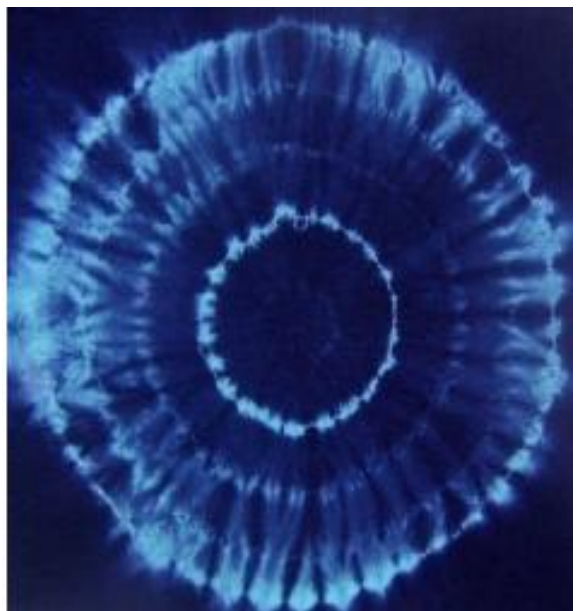

Figure 2.1 rotating flat seam tie-dye process

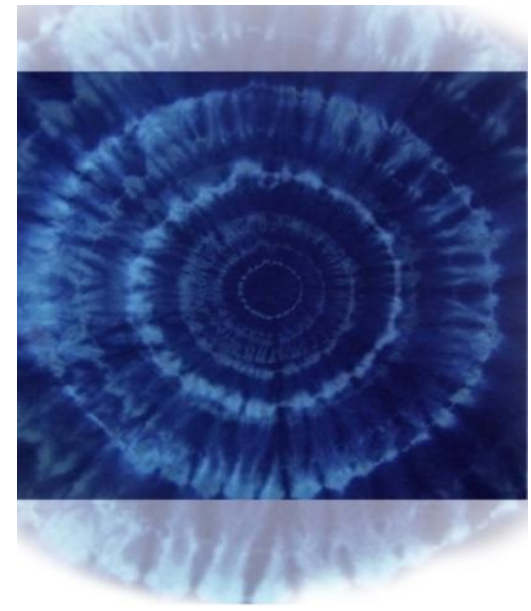

Figure 2.2 the pattern design of digital restructuring

Figure 2.2. to select a perfect pattern of single copy, rearranged in the new drawing. When copying can change the size of the pattern, change the pattern of the copy transparency, the new generation gradually dim level gradient color dyeing effect

\section{The Significance of Modern Tie Dyeing and Digital Art Blending}

First, from the point of view of the operation mode, the design of the electronic pattern of man-machine cooperation reflects the intelligence of the electronic technology in the traditional technology. Improving the quality and efficiency of pattern design by using computer software;

Secondly, computer software design has a huge advantage is the powerful storage function, the advantages constitute a rich and diverse tie pattern creation resources database. Computer can be used to greatly reduce the production time and proofing time, while reducing the cost of the process to reduce the cost of a large number of procedures. Will bring more market opportunities for enterprises.

Again, from the point of view of artistic effect, the modern dyeing pattern is a variety of styles, creative and dynamic multi-dimensional pattern texture. It breaks through the traditional tie dye patterns, maximize its rich graphic creativity, to meet the requirements of the times and personalized market call.

Digital technology revolution brings about the "design" of aesthetic feeling, and graphic elements of abstract and concrete by combining the popular color and harmonious combination as a whole image tells us that this artistic innovation is a new form of appreciation. (as shown in figure 3.1,3.2) 


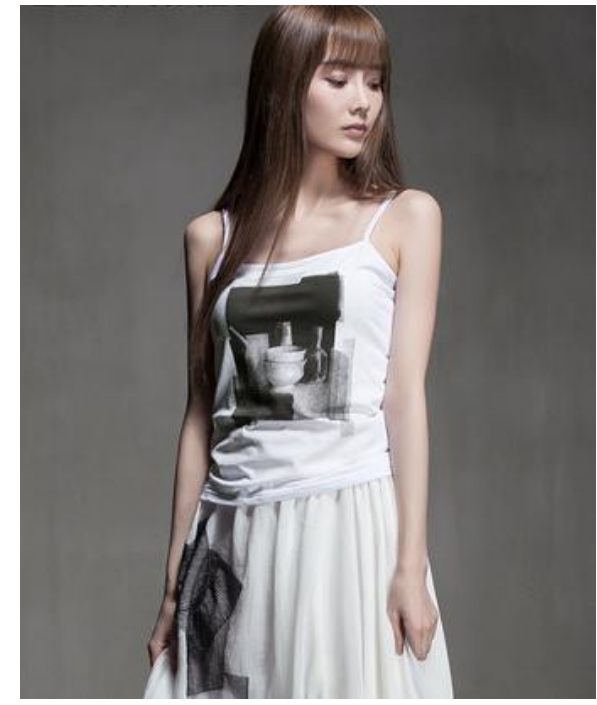

Figure 3.1 St Dior digital printing

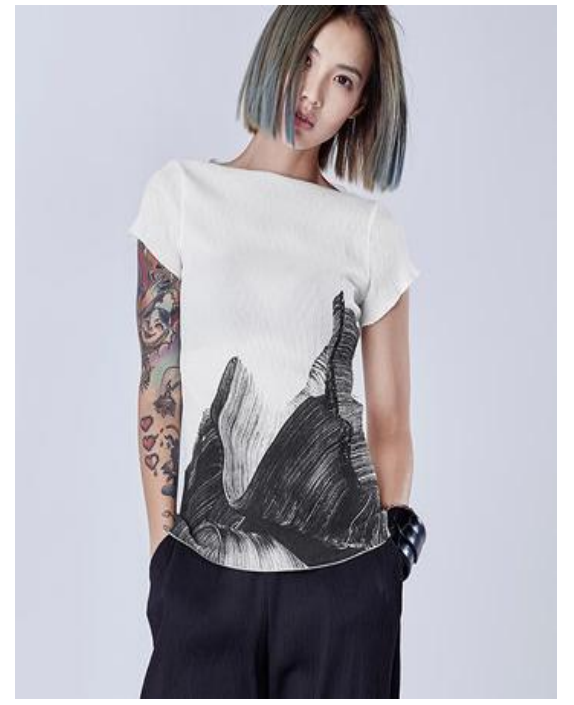

Figure 3.2 St Dior digital abstract pattern

Figure 3.1, 3.2 China's domestic growth in young brand Saint Dior's design, the use of digital art and traditional combination of patterns, deeply loved and recognized by young people. )

\section{Conclusion}

The advantage of computer aided design of digital art in graphic creation, is an important means of modern design pattern of contemporary fabric on the role can not be replaced by other means of design. So, for the modern digital art technology, high-tech means not only changed the pattern of the traditional mode of process and production level, also broke through the form of creative graphics, so that the traditional tie dye process into the pattern of our lives today and in the form of innovation for science and technology development in times of market demand, make it more suitable for natural the dyeing and finishing process of digital consumer functional and aesthetic requirements become fashionable and the trend of its future development goals. Has a good market prospects.

\section{Acknowledgements}

The educational reform in Jiangxi Province in 2015 "task driven teaching method in the" CorelDraw "clothing computer curriculum research and application" stage results, project number: JXJG15-26-5

\section{References}

[1] Che Weidong, Jin Chang Ying. Fabric reconstruction in the clothing design art performance of [J]. Textile Leader. 2011 (06)

[2] Ruan OME. Hand printed in fashion design application [D]. Donghua University 2014

[3] Cai Mufang. Design and application of textile digital printing pattern [D]. Jiangnan University 2007

[4] Tian Haiying. Application and Prospect of digital ink jet printing technology on textiles [J]. Printing quality and standardization. 2013 (05)

[5] Liu Zhongyu, Xu Bojun, she, she, she,. Application of digital printing in the creation of apparel [J]. Shanghai Textile Science and technology. 2013 (04) ()

[6] Zhang Junlong. Innovative technology leading digital printing Honghua digital image adaptive digital design system of [J]. Precision printing textile and Apparel Weekly. 2014 (02) 
[7] Zhang Weihai. Design and application of [J]. Digital printing dyeing and finishing technology patterns. 2016 (04)

[8] Liu Meng. Jesus textile digital printing the best printing effect [J]. International Textile Leader. $2016(03)$

[9] Li Hui, Liang Huie, Gu Ming. Fabric innovative design [J]. Silk from modern dyeing technology. 2010 (09)

[10] Wang Li. Realizing the traditional art tradition and innovation experience of passion activation [J]. Northern creativity: Discussion on dyeing technology of the 2002 (04). 